\title{
Os Lusíadas, de Camões, e a Peregrinação, de Fernão Mendes Pinto: perspectivas das viagens portuguesas
}

Lélia Parreira Duarte* 
A aproximação do ano 2000, com as conseqüentes comemorações dos 500 anos da chegada oficial dos portugueses às terras brasileiras, tem motivado releituras e revigorado discussões sobre literatura portuguesa de viagens. P retende-se reler aqui alguns aspectos de Os Lusíadas, de Camões, e da Peregrinação, de Fernão M endes Pinto, com o objetivo de observar semelhanças e diferenças em relação à perspectiva adotada diante dessas viagens. A escolha das narrativas se justifica por situarem-se ambas nas mesmas circunstâncias históricas, num tempo em que a esfera do divino se reduz, conquistado afinal pelo homem o reconhecimento da capacidade de entender e promover o mundo que se Ihe revela, sendo o incerto a margem dessa revelação.

As duas obras foram publicadas em momentos relativamente próximos - a epopéia de Camões em 1578 e a Peregrinação em 1614 (30 anos após a morte do autor) e em princípio deve-se assinalar uma grande diferença entre elas: Os Lusía das são uma epopéia que, como tal, faz uma narração de grandes feitos (embora não de forma ortodoxa); o relato de Fernão M endes Pinto é uma autobiografia que apresenta um espetáculo de miséria humana, com informações de conjunto sobre Oriente - Sião, China, J apão.

Os temas da epopéia são heróicos: fazendo o elogio dos lusitanos, que por "Obras valerosas / Se vão da lei da morte libertando", os Lusíadas celebram "as armas e os barões assinalados (...) Que passaram ainda além da Taprobana", e os reis que transformaram o mundo, "dilatando a fé e o império". Seu acontecimento central - a descoberta do caminho marítimo para as Indias -, é cantado em tom grandiloqüente, preocupado com uma realidade histórica épica e trágica, que pretende provar a grandeza dos lusitanos e a sua vocação para os grandes feitos que, 
segundo a epopéia, realizam-se em um relacionamento senhorial com povos mais fracos e submissos ou cordatos. Para essa exaltação, reaproveitam-se mitos alheios e criam-se outros, sendo o resultado a dramatização e transcendentalização de uma realidade que, não obstante, fica, sob a ficção, com apreensíveis grandezas histórica e poética.

Diferentemente, na Peregrinação os temas se intercalam e o foco não se restringe aos portugueses, haven do espaço também para os "outros". Aliás, a narrativa desnuda os preconceitos dos viajantes em referência aos povos visitados, vistos como mais fracos e submissos (indianos) ou mais fortes e poderosos (chineses). No relato de Fernão Mendes Pinto há ainda uma transumância pícara: seu narrador nada pretende provar, revelando, ao contrário, constantes problemas para a simples sobrevivência: o que seu relato em primeira pessoa consagra é o seu saber superior ao da coletividade, porque exprime experiência através de poder dizê-la.

A mbas as narrativas têm uma personagem principal: Vasco da Gama é o herói d’Os Lusíadas e António de Faria o anti-herói da Peregrinação, sendo que a profissão deste, conforme revela o relato, é apenas a de pirata, o que se comprova pelo assalto aos mausoléus dos reis da China na ilha de Calempluy (cap. IX).

Uma grande diferença entre os dois textos aparece também no campo da religiosidade: Os Lusíadas falam do temor a um Deus universal, renascentista, tirado do Novo Testamento; o cristianismo de Fernão Mendes Pinto é herético, sendo a religiosidade dos viajantes, revelada pela Peregrinação, amoral e particularista, muitas vezes criticada por personagens orientais, como o menino chinês da ilha dos Ladrões (episódio VI) ou o ermitão da ilha de Calempluy (episódio IX), que mostram o que há de bárbaro e particularista na mentalidade religiosa desses portugueses.

N'Os Lusíadas acentua-se o papel pedagógico dos heróis viajantes; na Peregrinação estes recebem ensinamentos ou são criticados, apresentando-se além disso a sugestão de que seu espírito é de pirataria. A crítica de Fernão Mendes Pinto faz-se, camufladamente, com referências ao exótico, através da descrição de práticas estranhas ou estúpidas dos orientais, equivalentes de alguma maneira às de seus compatriotas, preocupados em "comprar" a salvação eterna. E sse elemento exótico funciona ironicamente no texto como espelho da civilização do autor para criticar seus erros e absurdos ou para fantasiar modelos perfeitos que, pela apresentação espelhada do diferente, evidenciam seus aspectos negativos. Isso porque Fernão Mendes Pinto, mostrando ausência de preconceitos, constrói na China a sua utopia, a sua cidade ideal de sentido político, social e religioso. Contrariamente, a comparação que se faz dos portugueses com outros povos, n'Os Lusíadas, funciona sempre no sentido de engrandecer os lusitanos, com base no preconceito do grande amor próprio nacional. 
No centro da obra de Camões está o próprio Poeta / autor / personagem exemplar que, mostrando sua constante preocupação com o relato de grandes feitos, reune as verdades da experiência vivida, os ensinamentos da cultura recebida e a capacidade de os transformar numa nova significação totalizante, que se poderia resumir num sentimento exaltado de nação. Os Lusíadas constroem-se assim com um estilo entusiasmado em que o real positivo se acentua através da imaginação. E ncontra-se na epopéia um autor que quer ser reconhecido pelo seu canto, em que se reforça constantemente o eu, numa versificação rigorosa, que segue rigidamente um modelo, uma normalização. Colocando-se como humilde, baixo, rude, desconhecido, esse eu acentua entretanto que combina sabedoria, experiência e engenho - revelando mais um grande orgulho que modesta submissão.

Também no centro da fala da Peregri nação está o próprio escritor / autor / personagem, mas este não tem grandeza heróica: é um pícaro que não possui de seu mais do que pode ganhar com as mãos; não tem outro propósito na vida que não seja, em princípio, sobreviver e, depois, enriquecer, desconhece o preconceito de honra e faz questão de se exibir em situações convencionalmente desairosas. Para salvar a vida não recua diante de vilanias; mostrando (ingenuamente?) suas manobras para atingir ou conseguir o poder, chama-se a si próprio o "pobre de mim" e não se envergonha de servir de bobo. Em sua narrativa impassível de observador ingênuo (ou feroz?), a imaginação supera o que existe de real, de documento humano. Vejam-se como exemplos o relato do rapto da noiva chinesa ou o primeiro capítulo, com a narração da saída da casa do pai para a aventura da luta pela vida.

Ao estilo grandioso da epopéia contrapõe-se, portanto, o estilo humilde fingidamente ingênuo de quem não sabe o que está a contar - do pícaro, cujas narrativas são intercaladas de anedotas e palhaçadas de um autor que se faz de tolo, numa prosa falada de narrativa oral. Essa diferença é reafirmada quando, em ambas as narrativas, é passada a palavra a outros narradores: Os Lusíadas revelam mais uma vez seu esmero de plano e elaboração, ao entregar a narradores históricos e intradiegéticos (Vasco e Paulo da Gama) e a personagens míticos relatos que referendam uma perspectiva positiva para as viagens. Na Peregrinação, ao contrário, quando se dá a palavra a outros narradores, estes apresentam sempre perspectivas opostas às que seriam elogiosas para os portugueses, confirmando ironicamente (não claramente, portanto) a sugestão de denúncia presente na narrativa.

O modelo que a epopéia imita está no plano da teorização doutrinária da crítica e dos mecanismos de produção de textos, na esteira de uma literatura erudita, de problemática humanística classicizante. O caráter da Peregrinação, pelo contrário, marca-se muito mais como excêntrico a uma matriz histórica e/ou lite- 
rária determinada, integrando-se em modelos de contar medievais. Suas teses fundamentais incluem a sátira ao heroísmo, a afirmação repetida de que no Oriente os portugueses são bárbaros e os Orientais os civilizados, bem como a explanação da idéia de um deus superior aos cultos e aos ritos. Certamente por isso há na Peregrinação um excesso de copulativas (como se houvesse um nivelamento e não relevância de itens), marcando-se ironicamente a presença de subentendidos, muitas vezes através de mudanças de sujeito no corpo da frase.

A mbas as narrativas trabalham com intertextualidades: n'Os Lusíadas está a lição de poetas épicos (Virgílio, Homero, Ariosto) e de poetas trágicos (como António Ferreira); estão também coros semelhantes aos das tragédias gregas, as Metamorfoses, de O vídio, textos de H orácio, Francis B acon, J orge Ferreira de Vasconcelos e de cronistas portugueses, como Duarte Galvão, Rui de Pina, Fernão Lopes e Damião de G óis. Estão ainda dados da História dos descobrimentos e da Conquista da Índia, de Castanheda, e dos relatos de J oão de Barros, merecendo destaque o fato de ter a camoniana I Iha dos A mores traços comuns com a Utopia, de Thomas M orus, que a localiza numa ilha, fazendo-a encontrada por um pioneiro português. J á Camões transforma sua hipotética ilha num espaço imaginário que estivesse a aguardar ser de novo encontrado pelo jovem rei a quem dedicou o seu poema. Além disso, ambos os autores - Camões e Thomas Morus - dão um caráter pedagógico ao seu texto, com lições de como se deve governar, não fazendo portanto apenas elogios.

É curioso que também Fernão Mendes Pinto tenha feito em sua narrativa referências a textos característicos do Renascimento, como a mesma Utopia de Thomas Morus e a Nova Atlântida, de F rancis Bacon. E que, assim como Camões teve os seus Os Lusíadas imitados em outros textos, Fernão M endes Pinto parece ter tido a sua Peregrinação usada como modelo para narrativas irônicas do século XVIII: exemplos seriam as Lettres Persannes, de M ontesquieu, em que um persa em Paris critica, com espanto ingênuo, a cultura francesa da época, ou o Candide, de Voltaire, cujo herói percorre o mundo, ora encontrando estupidez profunda, ora exemplos de sabedoria em restos de civilizações. Trata-se de iluministas que tiveram em Fernão Mendes Pinto um precursor-modelo para a crítica da irracionalidade humana.

Além disso, a Peregrinação estará talvez mais presente que Os Lusíadas na literatura portuguesa contemporânea, em que numerosos textos retomam de forma ironicamente crítica as viagens e os descobrimentos. Como exemplos poder-seiam citar O bosque harmoni oso, de Augusto A belaira, Cantata para dois clarins e Peregrinação de um Barnabé das Índias, de Mário Cláudio, ou As naus, de António Lobo Antunes, que retomam a síntese artística de fundo picaresco realizada pela Peregrinação, a qual se marca, por exemplo, através de personagens/testemunhas 
ingênuas e/ou narradores com imagens de criaturas aparvalhadas e sem talento, ou com freqüente descarte da responsabilidade da narração feita. Ou aparece através do apelo a fontes duvidosas e autoridades inexistentes, da mistura de dados históricos verificáveis com erros de cronologia, de relatos de muçulmanos louvando o deus cristão ou pela presença de uma religiosidade hipócrita ou de verossimilhança questionável. (Catz, p. 283) . Veja-se ainda no texto a ambigüidade satírica ou, mesmo no maior exagero, a preocupação com um timbre de genuína veracidade. Interessante lembrar que, se o propósito crítico da Per egrinação se malogrou porque as autoridades da época não a entenderam, essa ausência de entendimento foi um triunfo da obra, garantindo a sua circulação.

Deve-se notar entretanto que também Os Lusíadas apresentam o seu aspecto crítico: está implícita na obra a intenção de recuperar o equilíbrio humanista entre a fé e a experiência, o espírito e a matéria, o apetite e a razão, as armas e as letras, numa nova ordem que não cabia num mundo em desconcerto. $M$ ais ainda: já anteriormente acentuei a presença do Poeta em seu poema (Duarte, 1988); também Helder Macedo demonstra que o Poeta intervém na narrativa através de recorrentes comentários que servem para caracterizar todos os outros narradores como ficção dramática de sua própria voz, ou para colocar o sentido global do poema na perspectiva crítica do presente. Com essas intervenções pessoais, Camões caracteriza seu discurso como voz do Poeta, que é o autor de Vasco da Gama, como se este e outras personagens do poema não tivessem outra existência além daquela que o texto poético lhes confere.

O discurso do Poeta mostra-se, assim, auto-referencial, definindo-se uma equivalência entre as suas experiências e as dos heróis que celebra no poema, às quais Camões acrescentou o seu feito maior: a capacidade de Ihes conferir significação nesse mesmo poema em que também se inclui. Dessacralizou assim a profecia, ao transpô-la do plano do "saber divino" para o finito mundo da linguagem em que se situa o humano entendimento. E mbora seu material seja épico, sendo seu tempo o da História, com viagens e demandas, guerras e conquistas, riquezas e poder, tem ele consciência de que a sua arte, para completar-se, precisa contar com a leitura, a percepção e o entendimento do outro.

A pesar das diferenças, parece existir portanto uma grande semelhança entre Os Lusíadas, de Camões, e a Peregri nação, de Fernão M endes Pinto, pois ambos contam com a percepção do leitor. Na verdade de sua poética, o poema épico também apresenta um texto que é mais da dúvida que da certeza, mais da ruptura que da continuidade, mais da imanência que da transcendência e, afinal, mais da fragmentação encontrada que da totalidade desejada. 


\section{Referências Bibliográficas}

CATZ, R ebecca. A sátira social de Fernão Mendes Pinto. Lisboa, Prelo, 1978.

CATZ, R ebecca. Fernão Mendes Pinto - sátira e anti-cruzada na Peregrinação. Lisboa, ICLP, 1981.

DUARTE, Lélia Parreira. Ironia: traço comum a Os Lusíadas e a O bosque harmonioso, de Augusto Abelaira. Boletim do Centro de Estudos Portugueses. n. 12. Belo Horizonte, FALE / UFM G, jul.1986/dez.1988, p. 150-156.

MACEDO, Helder. A poética da verdade d'Os Lusíadas. In: GIL, Fernando \& MACEDO, Helder. Viagens do olhar. Lisboa, Campo das Letras, 1998. p. 121-141.

PINTO, Fernão Mendes. Peregrinação.(Transcr. Adolfo Casais Monteiro). Lisboa, INCM, 1983.

SAR AIVA, António J osé. Fernão Mendes Pinto. 2. ed. Lisboa, Publicações Europa-A mérica, 1971. 


\section{resenhas}
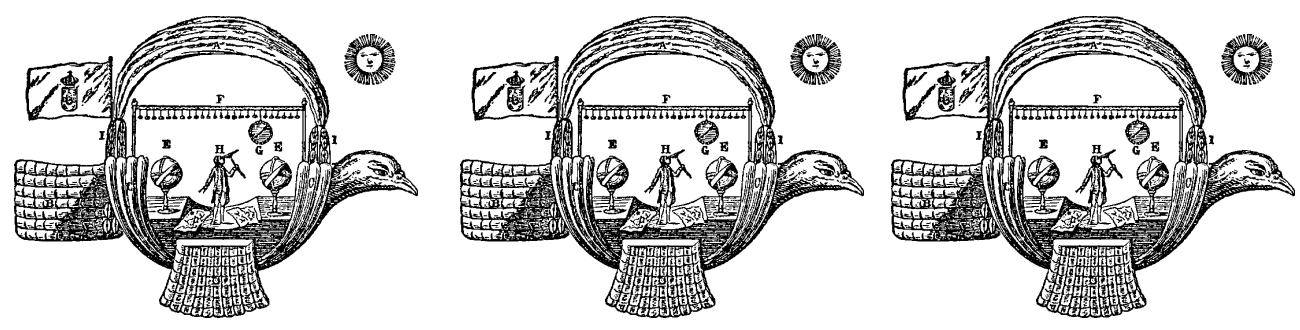